\title{
BEULAH: INTERMUNDO, SURREALIDAD. EL TERRITORIO DEL SUBCONSCIENTE Y LOS SUEÑOS EN EL MUNDO VISIONARIO DE WILLIAM BLAKE
}

\author{
Daniela Picón \\ Universidad de Chile/ Universidad Pompeu Fabra \\ danielapicon@gmail.com
}

RESUMEN / ABSTRACT

El poeta y artista inglés William Blake (1757-1827) situó el acontecer de su obra visionaria en una compleja cosmografía, que expresa parte importante del contenido simbólico de sus libros proféticos iluminados. Desde esta perspectiva, en este trabajo exploramos parte de dicho universo visionario, $\mathrm{y}$, concretamente, Beulah, la ingobernable región de la noche, el subconsciente y los sueños. Este territorio juega un rol fundamental en la reinterpretación que Blake formuló del mito de la Caída y la recuperación del Paraíso Perdido: Beulah es la zona que rodea la Eternidad y funciona como un intermundo que comunica recíprocamente la esfera superior e inferior de la existencia humana, es decir, el mundo Espiritual y Terrenal. Las sugerentes afinidades que es posible establecer con otras manifestaciones visionarias aparentemente tan distantes como la mística sufí y la práctica surrealista nos permiten comprender más ampliamente este mundo intermedio (Beulah, mundus imaginalis, surrealidad) donde la supresión de las leyes de la lógica y la razón posibilita la recuperación del estado creativo primordial de la conciencia -la imaginación- y permite la trascendencia del alma humana hacia su verdadera existencia.

Palabras Clave: William Blake, Beulah, mundo intermedio, sueño, visión.

The english poet and artist William Blake (1757-1827) places the events of his visionary work in a complex cosmography, which express an essential part of the symbolic content of his illuminated books. From this perspective, we explore part of this visionary universe, and, specifically Beulah, the ungovernable region of the night, subconscious and dreams. This territory plays a key role in Blake's reinterpretation of The Fall and the recuperation of the Lost Paradise: Beulah is the zone that surrounds Eternity and it works like an interworld that comunicates reciprocally the superior and inferior spheres of the human existence, that 
is, the Spiritual and the Worldly. Some suggestive affinities with other visionary expressions, apparently remote, like sufi mysticism and the surrealist practice can help us understand in a wider way this intermediate world (Beulah, mundus imaginalis, surreality) where the whithdrawal of the logical and rational laws makes the recuperation of the essential creative state of the conscience -that is, the imagination-possible and allows the trascendence of the soul to its true existence.

KEY WORDS: William Blake, Beulah, intermediate world, dream, vision.

Vivimos en los escombros del paraíso. De ahi que contemos con la esperanza de alcanzar el punto supremo

Michel Carrouges

Los libros proféticos iluminados de William Blake (1757-1827) son fruto de la intensa actividad visionaria que el poeta y artista inglés experimentó desde su infancia y a lo largo de toda su vida. El particular método de composición que él mismo inventó para transmitir sus visiones le permitió crear obras únicas y sorprendentes, en las que las imágenes y los textos se encuentran imbricados en una compleja dialéctica que exige una activa recepción por parte de sus lectores/espectadores, y se encuentra, por tanto, en total consonancia con el que fue su objetivo principal como profeta: "Abrir los Mundos Eternos, abrir los Ojos inmortales del Hombre al interior de los Mundos del Pensamiento, que están dentro de la Eternidad que siempre crece en el seno de Dios, la Imaginación Humana!"’.

Como librepensador radical, heredero de la tradición disidente inglesa, Blake consideró la religión cristiana desde una perspectiva crítica, y el mundo mitológico que desplegó en sus obras surge fundamentalmente a partir de dicha reflexión. Tres de sus poemas proféticos más importantes, Los Cuatro Zoas, Milton y Jerusalén, articulan en conjunto una reescritura, podríamos decir, del mito del origen del mundo, la Caída del hombre y sus posteriores intentos por recuperar el Paraíso Perdido.

1 "To open the Eternal Worlds, to open the Immortal Eyes/ Of Man inwards into he Worlds of Thought: into Eternity; Ever expanding in the Bosom of God, the Human Imagination" (Jerusalem 5: 18-20). 
En la reinterpretación que Blake realiza de este mito, el hombre, y particularmente la conciencia humana, constituye el tema central ${ }^{2}$, cuya historia $^{3}$ se desarrolla en un universo que tiene una participación directa en el acontecer: más allá de ser el escenario en el que transcurren los hechos y se desenvuelven los personajes, éste se presenta como agente interactuante del análisis que Blake expone en sus libros proféticos. Tanto los territorios geográficos como también los personajes que pueblan dichas regiones constituyen 'figuras' (Auerbach 1998), es decir, encarnaciones simbólicas, en este caso, de aspectos de la mente humana, de la vida interior de la humanidad y los distintos estados de la conciencia, como lo son, por ejemplo, la razón, la revolución y la ira ${ }^{4}$.

Desde esta perspectiva, en las páginas que siguen exploraremos parte de dicho universo visionario y, concretamente, Beulah, el territorio en que Blake situó simbólicamente las facultades del subconsciente y el sueño. En pleno siglo XVIII, un siglo de ambigüedades, pero en el que el racionalismo prevaleció en los dominios del pensamiento científico y filosófico, Blake, como prerromántico, les otorgó a estos imperios una sugerente importancia en un proceso que se plantea simbólicamente como la recuperación del Paraíso Perdido, y que, como veremos, se encuentra sometido a la evolución, o más bien, la regeneración de la conciencia del hombre.

2 Tal como señala Foster Damon, en la cosmografía blakeana el hombre es un todo en sí mismo cuya importancia supera incluso a la de la propia deidad, ya que esta última es considerada como el mayor poder del ser humano, es decir, la imaginación. Según Blake, 'Dios es hombre y existe en nosotros y nosotros en él', ambos son, por tanto, inseparables (William Blake: His Philosophy and Symbols 146).

Blake concibió la historia del alma individual en comunión con la del desarrollo humano, porque - de acuerdo a la teoría del macro y microcosmos-creía que toda la historia de la creación se repite en cada ser individual (Foster Damon. William Blake: His Philosophy and Symbols 62).

De allí que C. G. Jung utilizara algunas de estas imágenes blakeanas para ilustrar sus formulaciones teóricas sobre los arquetipos. A este respecto ver el estudio de June Singer: Blake, Jung, and the Collective Unconscious: The Conflict Between Reason and Imagination. York Beach: Nicolas Hays, 2000. 


\section{COSMOGRAFÍA ${ }^{5}$ DE LA OBRA VISIONARIA DE WILLIAM BLAKE}

El territorio de Beulah forma parte de una compleja geografía visionaria ${ }^{6}$, cuya organización, ya lo hemos dicho, debe comprenderse en estrecha relación, o más bien, como consecuencia directa del devenir de la historia de la mente humana, que es la que Blake relata.

Según la mitología blakeana, el hombre habitaba originalmente la Eternidad, el mundo infinito y verdadero, donde todas sus facultades se encontraban unificadas y convivían armónicamente en su interior, sin que existiera preponderancia de una sobre otra.

La tragedia de la humanidad no se originó, según Blake, porque el hombre cayera en pecado, sino en el error, un error que radicó fundamentalmente en la división de sus poderes y la consecuente dominación de uno de ellos por sobre los demás. Respondiendo críticamente a su propio contexto, Blake identificó a la razón como este tiránico poder que habría usurpado el lugar dominante, subyugando a todo el resto, entre ellos, la imaginación.

Como consecuencia de lo anterior, el alma humana habría caído desde el eterno paraíso en que habitaba originalmente, hasta el mundo creado por Urizen, el rey tirano de la razón en la mitología blakeana: un mundo finito y temporal, que se caracteriza, entre otras cosas, porque en él el hombre ya no puede desenvolverse instintivamente, sino según convenciones artificiales impuestas por la lógica, producto de la instauración de ciertas divisiones que no existían previamente en la Eternidad, como por ejemplo, aquella que distingue moralmente entre el bien y el mal, y sexualmente entre el hombre y la mujer.

5 No pretendemos realizar aquí una exposición detallada respecto a este tema, sino contextualizar brevemente la ubicación de Beulah en el esquema cosmográfico blakeano. Para un estudio más exhaustivo puede consultarse el capítulo "Cosmografía" del trabajo de Foster Damon, William Blake: His Philosophy and Symbols 140-153.

$6 \quad$ Henry Corbin utiliza el término 'geografía visionaria', proveniente de la mística persa, para referirse al simbolismo del paisaje del universo tangente en el que tiene lugar la experiencia visionaria. La tierra de las visiones es comprendida como un intermundo, "queriendo significar con esta última denominación que no se trata propiamente de un 'lugar' sino de la transformación de cualquier lugar por su contemplación a la luz visionaria”(Cirlot 222). 
La degeneración que el hombre sufrió, como resultado de este proceso, se expresa en el fraccionamiento de sus cuatro aspectos fundamentales o Zoas ${ }^{7}$ (el cuerpo, la razón, las emociones y la imaginación), que, tras la Caída, tomaron cada uno sus posiciones y se encuentran en permanente conflicto.

En la plancha 32 del Milton, Blake diseñó el diagrama del mundo temporal creado por Urizen. Los cuatro Zoas se representan como círculos entrelazados y de acuerdo al simbolismo geográfico, el visionario asignó un territorio, un punto cardinal y un astro, a cada uno, respectivamente:

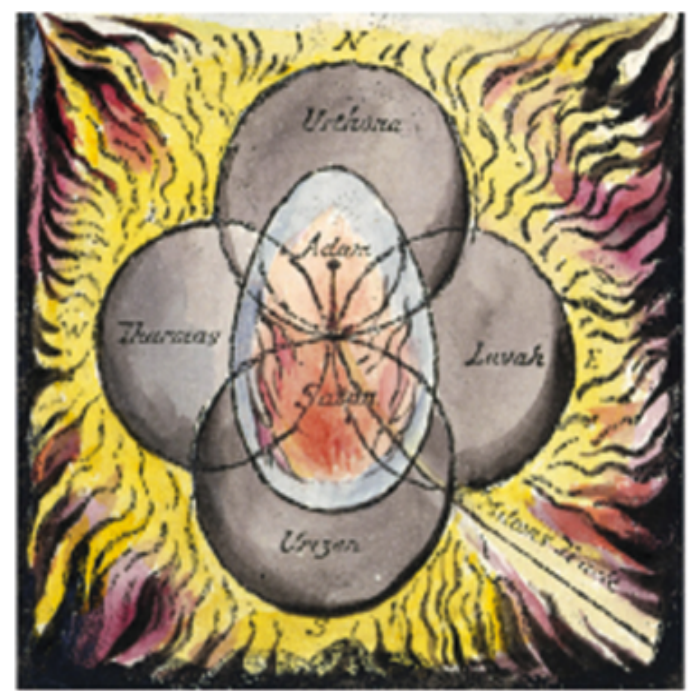

Milton, 32

Según este esquema, en el norte se ubica Urthona, Zoa que corresponde al reino del espíritu y está gobernado por el Sol. El este pertenece a Luvah, las emociones, región que está gobernada por la Luna. En el oeste se ubica el reino del cuerpo con sus sentidos, Tharmas, Zoa que es gobernado por la

$7 \quad$ Zoa es un vocablo griego que Blake traslada al inglés en forma plural. En el libro de las Revelaciones es traducido como 'bestias': las cuatro bestias que Juan de Patmos vio junto al trono de Cristo, y corresponden a las 'criaturas vivientes' del libro de Ezequiel. En la iconografía convencional son representadas con rostro de hombre, león, buey y águila, y se identifican comúnmente con los cuatro evangelistas (Foster Damon, A Blake Dictionary 458). 
Tierra. Por último, el desértico sur corresponde a Urizen, la Razón, el dominio intelectual gobernado por las estrellas.

En el centro, Blake ha dispuesto la imagen del 'Huevo mundano', símbolo cósmico que, tal como señala Juan Eduardo Cirlot, se encuentra en la mayoría de los mitos tradicionales de creación (252) ${ }^{8}$. El 'Huevo' corresponde al mundo cuatridimensional en el que vive el hombre desde su Caída y hasta que logre reintegrarse a la Eternidad ${ }^{9}$. Éste se encuentra delimitado por la 'cáscara mundana" ${ }^{10}$, que es nuestro cielo visible y corresponde a la frontera entre el 'huevo mundano' y los cuatro universos, o Zoas, que lo rodean ${ }^{11}$.

La instauración de esta 'cáscara mundana' constituye quizás la peor de las consecuencias de la Caída para la humanidad, ya que demarca los límites que Urizen impuso a las facultades del hombre, que solo puede utilizar parcialmente en el mundo terrenal. En otras palabras, esta 'caparazón' interpone una determinante frontera entre dos mundos que se tornan contrapuestos: el de la imaginación, en el norte, identificado con la Eternidad o existencia verdadera, donde todas las facultades de la conciencia del hombre -o Zoasconviven en armonía y de las cuales éste dispone libremente; y el sur, donde se ubica el mundo material, que Blake denominó Ulro, el mundo de la razón, un territorio que los hombres erróneamente consideramos como real, pero

8 En la obra visionaria de la religiosa benedictina Hildegard von Bingen (1098-1179) también encontramos una sorprendente representación de la imagen del mundo como un huevo cósmico, simbolizando su carácter de totalidad dinámica (Scivias I-3).

$9 \quad$ Como puede verse en la imagen, la porción inferior del huevo está ocupada en su mayor parte por Urizen (Satán), cuyas llamas ascienden hasta la mitad superior del huevo, donde se ubica el reino de Urthona (Adán).

10 En Milton (19:21-25) la 'cáscara mundana' es descrita de este modo: “The Mundane Shell, is a vast Concave Earth: an immense/ Hardend shadow of all things upon our Vegetated Earth/ Enlarg'd into dimension \& deform'd into indefinite space,/ In Twenty-seven Heavens and all their Hells...". Cit. en Foster Damon, A Blake Diccionary 288.

11 La relación entre el 'huevo mundano' y los Cuatro Universos o Zoas, se explica en Milton (21:15-24): "Four Universes round the Mundane Egg remain Chaotic/ One to the North, named Urthona: One to the South, named Urizen:/ One to the East, named Luvah: One to the West, named Tharmas/ They are the Four Zoa's that stood around the Throne Divine!/ But when Luvah assum'd the World of Urizen to the South:/ And Albion was slain upon his mountains, \& in his tent; / All fell towards the Center in dire ruin, sinking down./ And in the South remains a burning fire; in the East a void". 
que no es más que artificio, un mundo finito, creado, gobernado y restringido por la razón ${ }^{12}$.

No obstante, Blake defendió la posibilidad que todo individuo tiene de superar los límites de la percepción sensorial de la esfera racional de la naturaleza y así trascender hacia el mundo de la Eternidad. Esto, a través del uso de su imaginación, una facultad de carácter humano-divino que, Blake afirmó, 'reside en el pecho de todos los hombres'. Esta convicción que se encuentra en la base de toda su obra, se resume y fundamenta en una de sus consignas más difundidas: "La imaginación no es un estado, es la existencia humana en sí misma ${ }^{13 "}$ " (Milton 32).

Así, mientras la humanidad se encuentre apresada entre los estrechos límites de la 'cáscara mundana', Beulah, un tercer plano de existencia, que se encuentra entre los mundos opuestos de la Eternidad y Ulro, funcionará como el territorio que favorece esta mediación que ejerce la imaginación, a modo de un 'pasaje' que comunica, en ambas direcciones, lo eterno y lo material.

\section{BEULAH: PARAÍSO TERRESTRE, MUNDO INTERMEDIO}

Beulah es una palabra hebrea que significa 'casada', 'amada' ${ }^{14} \mathrm{y}$, en el Libro de Isaías (62:4) es el nombre dado a Palestina cuando ésta es restituida al favor de Dios ${ }^{15}$.

Beulah existe también en la obra alegórica de John Bunyan, El Progreso del Peregrino, texto que tuvo una enorme difusión en los países protestantes

12 La contraposición entre ambos mundos bien se expresa en este pasaje de Una Visión del Juicio Final: "Este mundo de la Imaginación es el mundo de la Eternidad; es el seno divino al cual regresaremos después de la muerte de nuestro cuerpo vegetativo. Este mundo de la Imaginación es Infinito y Eterno, mientras el mundo de la Generación, o Vegetación, es Finito y Temporal". A Vision of The Last Judgment. Erdman, The complete Poetry and Prose of William Blake 555. Traducción libre de la autora.

13 Esto debe comprenderse en directa consonancia con lo que ya planteábamos en la nota 2 de este trabajo, es decir, la correspondencia que Blake plantea entre Dios, la imaginación $\mathrm{y}$ el hombre.

$14 \quad$ Ver Foster Damon, A Blake Diccionary 42.

15 “(...) tu tierra se llamará Beulah: porque el amor del Señor estará en ti, y tu tierra será desposada". Isaías 62: 4. 
de lengua inglesa ${ }^{16}$. La tierra de Beulah es en la obra de Bunyan el Paraíso Terrestre, de donde proviene, por tanto, la idea de que constituye un territorio que limita con el cielo, como frontera terrestre entre lo temporal y eterno: Beulah es la antesala de la ciudad celestial, locus amoenus, cuyo 'aire es dulce y agradable', especialmente propicio para el descanso de los peregrinos ${ }^{17}$.

En la geografía visionaria de Blake, Beulah también es la zona que rodea la Eternidad, es el Paraíso Terrestre, que, como veremos, se plantea como un intermundo, es decir, una región que comunica recíprocamente el mundo Espiritual y Terrenal.

Según Blake, la cuádruple división que sufrió la conciencia humana tras la Caída, también afectó al poder visionario del hombre, que se encuentra fragmentado en cuatro clases de visiones, cada una de las cuales corresponde a un Zoa. En una carta escrita a Thomas Butts, Blake las distinguió de este modo: "Ahora tengo una cuádruple visión,/ y una cuádruple visión me ha sido dada; /Ésta es mi deleite supremo,/ Y triple en la suave noche de Beulah,/ Y siempre doble. Que Dios nos Guarde/ De la visión individual, y del sueño de Newton ${ }^{18 "}$. (Erdman, The Complete... 722). Blake plantea aquí una gradación de los distintos tipos de visión ${ }^{19}$, de acuerdo a las experiencias místicas que él mismo experimentó como parte normal de su vida. Tal como explica Foster Damon (A Blake Dictionary) la visión individual (la de Newton) no constituye una 'visión' propiamente tal, sino simplemente la observación del mundo material mediante los ojos físicos, "te lleva a creer en una mentira/ cuando

16 Donde se convirtió, según señala Delumeau (591-593) en una suerte de 'Biblia del pueblo'.

17 "Aquí nuestros peregrinos no padecían ninguna carencia de trigo o de vino, pues encontraban en abundancia todo lo que habían buscado en vano durante su peregrinaje (...) había en su camino vergeles, viñas y jardines cuyas puertas estaban abiertas (...) Los viajeros descansaron y durmieron ahí". Cit. en Delumeau 593 y 594.

18 La traducción es nuestra.

19 Se trata de una distinción que San Agustín expuso de manera decisiva para la posteridad en el libro XII de su Del génesis a la letra. En él concibe tres géneros de visiones: corporal, espiritual e intelectual. "Una es la de los ojos con los cuales se contemplan las letras; otra la del espíritu del hombre por la que se piensa en el prójimo ausente; la tercera tiene lugar en la mirada atenta de la mente con la que se contempla la misma dilección". En: Obras de San Agustín. Madrid: Biblioteca de Autores Cristianos, 1950. 971-2. Así, la visión corporal es aquella con la cual todos contemplamos el mundo físico y material que nos rodea, mientras que la espiritual es la que se produce a partir de las imágenes archivadas en el alma. La tercera clase de visión, la intelectual, es sin duda la más críptica, definida por San Agustín como aquella que se da en la mente, sin concurrencia de imágenes. 
miras con, y no a través del ojo" (Cit. en Foster Damon 436). La "visión doble' es ver 'a través' del ojo, es la percepción de los valores simbólicos del mundo material (437). La 'triple visión', que tiene lugar 'en la suave noche de Beulah', es el estado creativo, donde el pensamiento aparece en forma emocional (437). La 'cuádruple visión', por último, es el 'deleite supremo' del visionario, el éxtasis místico, que se consigue cuando en el hombre se reintegran todas sus facultades y éste vuelve a reunirse con Dios, en una sola existencia (291).

Beulah constituye, entonces, el plano espiritualmente más alto al que los mortales podemos aspirar, gracias a que posibilita un tránsito desde lo terrenal a lo espiritual que nos acerca al reino de la Eternidad: la imaginación. En un sentido inverso, asimismo, Beulah funciona como un territorio gracias al cual los Eternos pueden descender ${ }^{20}$ y tomar contacto con el mundo material, porque allí le son otorgadas las formas corporales que les permiten desplazarse a través de él.

Las sugerentes correspondencias que a este respecto se pueden establecer entre el pensamiento blakeano y la tradición, aparentemente tan distante, del misticismo sufí, nos permitirán profundizar en nuestra comprensión de este plano intermedio. Siglos antes que Blake, el poeta místico Ibn Arabí (11651240) distinguía también el plano superior (inteligible) e inferior (sensible) de la existencia, y ubicaba entre ambos el nivel de la imaginación, inteligible y sensible a la vez, que denominó como "el lugar de las infinitas cosas posibles" (Adonis 90). El islamista y filósofo Henry Corbin lo designó como mundus imaginalis, un mundo en el que "... se corporifican los espíritus y se espiritualizan los cuerpos", donde la imaginación, que "pone en relación de simpatía lo invisible y lo visible, lo espiritual y lo físico" (Corbin 185) posibilita el acontecer de la creación visionaria ${ }^{21}$. Tal como ha señalado Victoria Cirlot, la idea del mundo intermedio proyectado por Corbin se opone a la de la imaginación en su acepción sartreana, la que, al estar articulada a partir de la percepción del mundo sensible, se encuentra dotada de un carácter altamente 'irreal'. El espacio intersticial híbrido de Corbin, por el

20 Como lo hizo Milton y Ololon, una de sus Hijas, para visitar a Blake mientras éste paseaba por un jardín en Felpham. Respecto a estas visitas espirituales ver: Foster Damon, William Blake: His Philosophy and Symbols 148-9.

21 En la cosmografía blakeana, uno de los accesos a Beulah se encuentra, significativamente, en Golgonooza, la ciudad de las artes, y se encuentra custodiado por místicos como Fénelon, Teresa y Whitefield. 
contrario, es de raíz platónica, es decir, provee de las imágenes que, por su semejanza, confieren de identidad a las formas de este mundo, tal como el iranólogo las vio ilustradas en algunas miniaturas de finales del siglo XIV (Cirlot, La visión... 66).

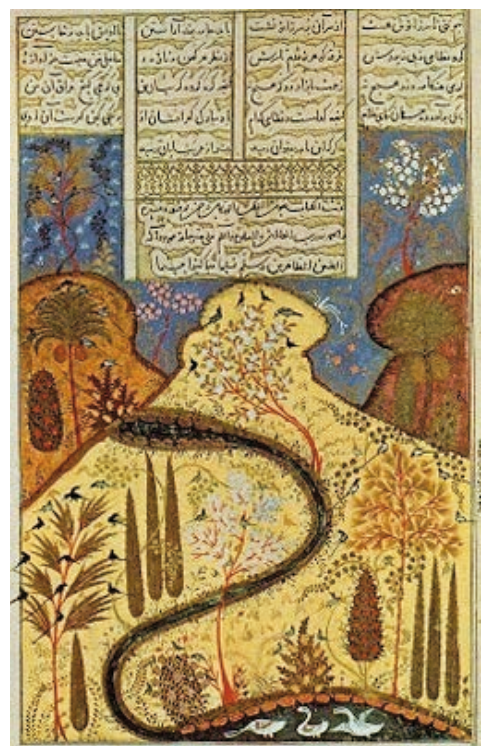

Paisaje místico persa (s. XIV)

Beulah, el mundo intermedio en la cosmografía blakeana, es además la región de la noche y los sueños. En Los Cuatro Zoas (I: 30-37), Blake describe Beulah como un lugar 'de dulce y agradable descanso (...) un suave y encantador Universo femenino, iluminado por la luz de la Luna, donde la dulzura pura y la suavidad le son dadas en misericordia a aquellos que duermen eternamente' (Erdman, The complete Poetry and Prose... 303) 22.

Beulah se presenta en este pasaje como la región de la noche, dominada por la Luna, que simboliza las emociones, y en particular, el $\operatorname{amor}^{23}$. Ya que la Luna también es símbolo del sueño y el inconsciente, algunos autores ${ }^{24}$ han

22 La traducción es nuestra.

23 Foster Damon, A Blake Diccionary 285.

24 Como comenta en su traducción Xavier Campos, Jerusalén 207. 
interpretado esta zona como alegoría del subconsciente humano. De hecho, si revisamos las características de su geografía, notamos que entre los valles, arroyos y montañas hay cuevas provistas de lechos de oro especialmente dispuestas para los durmientes, a quienes las Hijas de Beulah cuidan con 'amor maternal' mientras éstos descansan entregados a los sueños (Milton 28: 49) entre suaves melodías (Milton 34: 10).

La Luna de Beulah también representa la porción femenina del Sol, estrella superior que ilumina la Eternidad, siendo ésta la que refleja el resplandor de la imaginación en un mundo nocturno, que a su vez, constituye una fuente constante de inspiración para los habitantes del mundo temporal. Desde esta región, visiones y sueños descienden a Ulro, como inspiraciones nocturnas, que pueden presentarse, entre otras formas, como rayos (Milton 15: 44) o vientos, cuya intensidad incluso llega a arrancar rocas y montañas (Milton 7, 33).

Desde muy antiguo se ha considerado a los sueños como un medio de inspiración y revelación que posibilita el florecimiento de las facultades irracionales del imaginario, por lo que el pensamiento de Blake debe inscribirse en esta larga tradición que vincula la actividad onírica con la creación artística. Alois M. Haas, por ejemplo, ha reflexionado sobre su presencia en las Sagradas Escrituras y la valoración visionaria que se les otorgó durante la Edad Media, particularmente en el contexto de la mística femenina alemana ${ }^{25}$. Por otra parte, si volvemos a la espiritualidad sufí, también reconoceremos el rol fundamental que se les confiere, ya que los sueños acontecen en “ (...) un estado que traslada al ser humano desde la contemplación del mundo sensible al mundo intermedio (barzaj)" (Adonis 100), es decir, al mundo

25 Haas da cuenta de las divergencias existentes sobre la valoración mística de los sueños en este contexto: “... entre los dominicos predomina la idea de que las visiones corporales e imaginales tenían que ser abandonadas en lo posible a favor de la intelectuales; entre las dominicas, por el contrario, los tipos de visiones rechazados, los corporales e imaginales, son los que parecen acuñar el ambiente monástico en una espontaneidad en modo alguna refrenada" (28). Estas autoras, continúa, Haas, no distinguieron, por lo general, entre visiones y sueños, lo que puede advertirse recurrentemente durante toda la Edad Media. La confianza medieval en los sueños se sostiene, según Haas, en su comprensión como una fuente de conocimiento velado “... fue siempre evidente que los sueños, de cualquier tipo que fueran, pertenecían al contexto de una doctrina de los signos. Los sueños son signa, vera los que provienen de Dios, falsa los que provienen de los demonios" (13). No obstante, continúa Haas, esto no quita que se les haya mirado con desconfianza: el Maestro Eckhart, por ejemplo, no vio con optimismo su interpretación y siempre se mostró receloso frente a las formas de teofanía concreta (15). 
de la creación. El poeta sirio Adonis establece una correspondencia entre los sueños y el mundo de la imaginación, porque "Cuando la persona está dormida, la visión se dirige hacia el mundo de la imaginación, que es el más perfecto de los mundos, el origen del mundo, ya que posee la existencia verdadera" (Adonis 100), la 'existencia humana en sí misma', diría Blake.

Los sueños fueron valorados de manera semejante por los poetas y artistas románticos contemporáneos a Blake ${ }^{26}$, quienes recurrieron a éstos con el fin de abrir el alma a la experiencia interior y así posibilitar su reencuentro con la Unidad universal ${ }^{27}$, considerando: “. .. la Noche, guardiana de los tesoros, el Inconsciente, santuario de nuestro diálogo con la realidad suprema, el Sueño, en que se transfigura todo espectáculo y en que toda imagen se convierte en símbolo y en lenguaje místico" (Béguin 77).

Desde la primera mitad del siglo XIX, el interés por el estudio del inconsciente y el modo en que éste se manifiesta en la vida psíquica hizo que el discurso sobre el sueño comenzara a tomar forma en París, donde se hizo dominante en la segunda mitad del siglo, con la publicación de investigaciones como las de Alfred Maury, recolectadas en 1861 bajo el título de Le sommeil et les rêves (Heraeus y Cohen 153).

Algunos años más tarde, en el contexto de las vanguardias europeas del siglo XX, y tras de la aparición de las teorías psicoanalíticas del sueño, la actividad onírica constituirá una herramienta fundamental en la exploración que los surrealistas realizarán del subconsciente, con el objetivo -afín al romántico-de descubrir los territorios más auténticos de la existencia humana. Así lo expresó André Breton: "Deseo que [el Surrealismo] sea considerado por no haber intentado nada mejor que tender un hilo conductor entre los mundos excesivamente disociados de la vigilia y del sueño, de la realidad exterior e interior, de la razón y de la locura, de la calma del conocimiento y del amor, de la vida por la vida y de la revolución, etc." (Los vasos comunicantes 76).

En la plancha 41 de Jerusalén, William Blake asocia directamente el momento de la escritura inspirada con el sueño ${ }^{28}$ :

26 A este respecto puede consultarse el ya clásico estudio de Albert Béguin: El alma romántica y el sueño. México: Fondo de Cultura Económica, 1954 (1939).

27 Asunto al que Novalis dedicó su colección de poemas Himnos a la noche.

28 Sigo en parte una de las interpretaciones que W. J. T. Mitchell da a esta plancha en Teoría de la imagen 122-4. 


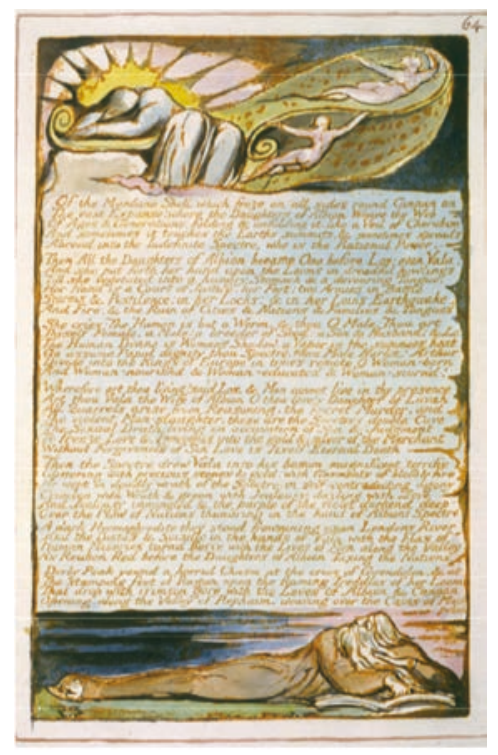

Jerusalén, 41

El escriba del extremo superior se ha dormido sobre el pergamino que le sirve como soporte de escritura. Abajo, y de manera opuesta, la figura despierta está inmersa en un libro, pero se distrae con las encantadoras hadas que se le presentan en visiones al durmiente. Varias señales simbólicas propias de la imaginería blakeana permiten interpretar esta escena como emblema del estatus imaginativo superior que el visionario inglés le otorga al escriba dormido, cuyos fértiles sueños contrastan con la estéril vigilia del lector en el inferior ${ }^{29}$.

En Los cuatro Zoas, en tanto, 'Las Hijas de Beulah [es decir, de la inspiración nocturna] siguen a los durmientes en todos sus sueños' (1: 208) que son concebidos como una genuina y fecunda fuente de inspiración. Prefigurando en gran medida la preferencia romántica por lo nocturno y los sueños, Blake reconoció que la inspiración lo inundaba especialmente durante las noches o al despertar, y que lo mantenía escribiendo y dibujando sin detenerse, por lectura que utilizan (el pergamino y el libro), su estado de conciencia (sueño y vigilia), su apariencia física (juventud y vejez), y la atmósfera que los rodea (luz y tinieblas), entre otros. Ver Mitchell 122 y ss. 
largas horas. Así lo describe al referirse a la composición de Jerusalén: "Este tema me llama noche tras noche mientras duermo, y todas las mañanas me despierta cuando sale el sol; luego veo al Salvador que esparce sobre mí sus rayos de amor y dicta la letra de esta suave canción" (58: 61). Otro hecho que confirma la importancia que Blake otorgó a la inspiración obtenida de los sueños es que en dos de sus poemas proféticos más importantes, Los Cuatro Zoas y Milton, la invocación épica a la musa está dirigida a las Hijas de Beulah, y no a la clásica hija de la memoria, cuyo influjo se concibe como una repetición no original, en oposición a la inspiración directa que otorgan los sueños $^{30}$. Así, al abrir Milton, Blake pide a las Hijas de Beulah que desciendan hasta su cerebro y continúen desplazándose por su brazo derecho, que es el que empuña la pluma: "¡Hijas de Beulah! Musas que inspiráis el Cantar del Poeta, (...) Venid a mi mano Por vuestro dócil poder; los Nervios descended de mi diestro brazo Desde el Portal de mi Cerebro (...)" (1:1).

Testimonios de este tipo, presentes tanto en los poemas como en las cartas que Blake envió a sus amistades, además de la condición semi-dormida en que generalmente escribía y dibujaba sus visiones, son factores que la crítica ha tenido presente a la hora considerar si su método de composición corresponde al de la escritura automática, procedimiento creativo que utilizaron $\tan$ recurrentemente los surrealistas ${ }^{31}$. Blake aseguró en reiteradas ocasiones que los espíritus 'dictaron' sus poemas y al referirse a la composición de Milton afirmó: "He escrito este poema a partir de un dictado inmediato (...)

30 La inspiración obtenida de fuentes como la tradición y los libros se considera secundaria. Ver: Foster Damon, A Blake Diccionary 43 y Erdman, The Complete Poetry \& Prose 948 n. Debemos tener en cuenta que, en el contexto del prerromanticismo, Blake consideró la memoria como parte de nuestro cuerpo mortal, opuesta, por tanto, al verdadero sentido espiritual de la inspiración e imaginación. Así lo expresó varias veces a lo largo de su obra: en el prefacio de Milton, "Las Hijas de la Memoria se convertirán en Hijas de la Inspiración", mientras que en Jerusalén, "El Espectro es el Poder Razonador que hay en el Hombre, y cuando se separa de la Imaginación y se encierra como rodeado de acero en una Proporción de las Cosas de la Memoria, a partir de ese momento desarrolla Leyes y Sistemas Morales para, mediante Martirios y Guerras, destruir la Imaginación, el Cuerpo Divino" (154-155). En el Catálogo Descriptivo "Las Musas Griegas son las Hijas de Mnemosyne o la Memoria, y no de la Inspiración o Imaginación, por lo que no son las autoras de estas concepciones sublimes". Cit. por Bel Atreides, Milton 261. En Una Visión del Juicio Final, por último, "La fábula o alegoría son un tipo totalmente distinto e inferior de poesía. La Visión, o Imaginación, es una Representación de lo que existe eterna, real, e inmutablemente. La Fábula o Alegoría son formadas por las Hijas de la Memoria". Erdman, The Complete Poetry \& Prose 554.

31 Ver el estudio recientemente publicado de Mei-Ying Sung: "Blake and Surrealism". 
sin premeditación e incluso contra mi voluntad" (Erdman, The Complete Poetry \& Prose... 729), lo que lo llevó a autodenominarse como 'secretario de la Eternidad' ${ }^{32}$. No obstante, las interminables enmiendas y correcciones que realizó a los textos en su Notebook demuestran que éste no transcribía mecánicamente aquello que le venía al dictado ${ }^{33}$. Por esto, Foster Damon (William Blake: His Philosophy and Symbols 205) ha planteado que es más apropiado pensar que su poesía surge, más bien, de una lucha entre conciencia y subconciencia, durante la cual Blake intentó corregir sus impulsos poéticos irregulados.

Ahora bien, más allá de la posible 'interferencia' que el visionario haya podido ejercer durante la transcripción de los mensajes que le fueron revelados, lo significativo es que, efectivamente, el modo en que éste comprendió la visión y la escritura es muy asimilable a la propuesta surrealista de la composición automática (Mei-Ying Sung 104). Esta técnica, utilizada tanto en la pintura como en la literatura, fue valorada como un ejercicio que permite adentrarse en las profundidades desconocidas del subconsciente, ya que, según planteó André Breton "... ofrece una llave capaz de abrir indefinidamente esta caja de doble fondo a la que llamamos hombre" (Breton y Eluard, Diccionario 18). La clave de la escritura automática radica en la asociación libre, que enfatiza la búsqueda de una liberación mental con el fin de expresar el ser interior verdadero ${ }^{34}$. Por ello, los surrealistas buscaron la suspensión total de

32 Mitchell, W.J.T. Picture Theory 139-40.

33 Tal como señala Michaell Phillips (15), el estudio del extenso proceso de producción de los libros visionarios de William Blake -que va desde los manuscritos hasta la elaboración de las copias impresas- permite demostrar que éste no compuso sus obras de una manera impremeditada, o como respuesta inmediata a un dictado divino. Si bien la ausencia de los bosquejos o de evidencias manuscritas, apunta Phillips, ha hecho pensar que Blake compuso su poesía y diseños directamente sobre sus planchas de cobre, sin previa meditación, el estudio de los manuscritos de las Canciones nos lleva a conocer a un compositor de poesías y diseños lleno de dudas y vacilaciones, de rechazos y de una preocupación meticulosa. Esto puede apreciarse claramente también en su libro de anotaciones: "The Notebook". British Library. Online Gallery. Virtual Books. (23/04/2012). http://www.bl.uk/onlinegallery/ttp/ blake/accessible/introduction.html

34 Breton sentó las bases del automatismo en el Primer Manifiesto Surrealista de 1924, aunque en su primera obra, publicada en conjunto con Phillipe Soupault, Los Campos Magnéticos (1920) ya había explorado en esta técnica. Otros procedimientos creativos surrealistas como el "cadáver exquisito", el collage y el frottage favorecían de forma equivalente, tanto desde la poesía como desde la plástica, la exclusión de toda actividad e intervención consciente del poeta $\mathrm{y} / \mathrm{o}$ artista. 
la actividad racional en el hombre, valorando la espontaneidad y autonomía que ofrecen la visión y los sueños, fuentes de inspiración que también fueron reivindicadas por Blake (Mei-Ying Sung 104).

William Blake concibió la noche y la madrugada como instancias de especial predisposición para la experiencia visionaria, justamente aquellas horas durante las cuales existe mayor indeterminación entre los estados de vigilia y sueño, y propician, por tanto, un acceso más inmediato al inconsciente ${ }^{35}$. De ahí entonces, el que legitime Beulah, el reino de los sueños, como una fuente de inspiración poética y visionaria, y que se trate de una región que actúa, además, como un verdadero 'vaso comunicante' -si utilizamos la expresión de André Breton- entre los estados extremos -inferior y superior- de la conciencia humana: la razón y la imaginación.

En total consonancia con lo anterior debemos comprender que Blake le confiera a Beulah una función fundamental respecto a la recuperación del Paraíso Perdido. Como señalábamos más arriba, en el mundo mitológico de sus libros proféticos, Blake postula que desde su Caída el hombre habita en los dominios de la razón, o 'huevo mundano', un territorio en que ésta habría instaurado una serie de divisiones artificiales (entre lo real y lo irreal, la locura y la cordura, el alma y el cuerpo, etc.), restringiendo, por tanto, el desarrollo instintivo del hombre, gracias a la implantación de un código arbitrario de valores morales, conocidos convencionalmente como "Lo Bueno", o la energía que actúa conforme a las imposiciones de la razón, y "Lo Malo", es decir, la energía que actúa libremente.

El famoso lema blakeano, 'sin contrarios no hay progreso', responde justamente a la convicción de que la reconciliación de estos contrarios es una de las condiciones esenciales para que el hombre pueda desvelar los límites de este mundo artificial y recuperar así el verdadero paraíso. Beulah, el mundo intermedio de la noche y los sueños, se presenta como el escenario que posibilita esta síntesi ${ }^{36}$ necesaria para la trascendencia hacia la Eternidad. En sus dominios, al igual que en el intermundo de la mística

35 La noche fue utilizada como momento esencial de creación por los poetas y artistas románticos. El psiquiatra Carl Gustav Jung recogió en su Libro Rojo (cuyo formato es muy cercano a los libros proféticos iluminados de Blake) las experiencias visionarias que vivenció ejercitando su imaginación activa durante las noches, momento en que el rebajamiento de la conciencia permite la liberación del inconsciente (El Libro Rojo. Edición facsimilar en castellano: Buenos Aires: El Hilo de Ariadna Malba- Fundación Constantini, 2010).

36 Milton 30:1 y Jerusalén 48: 14. Ver: Foster Damon, A Blake Dictionary 42. 
sufí “... se confirma la incapacidad de la razón, así como la posibilidad de que los contrarios se unan" (Adonis 96). Esto, gracias a que se trata de un territorio que se encuentra totalmente liberado de las exigencias de la lógica ${ }^{37}$, como el inconsciente humano.

La analogía que es posible establecer con lo que Breton determinó como el objetivo supremo de la actividad surrealista en el pasaje de Los vasos comunicantes que ya hemos citado es evidente, $\mathrm{y}$, tal como ha señalado Victoria Cirlot, la imagen surrealista, que surge de la aproximación de dos realidades distantes, responde al mismo propósito, es decir, la conciliación de los contrarios.

Todas estas propuestas tienen su origen en una certeza compartida, que podemos reconocer en el Manifiesto surrealista de 1930: "Todo conduce a creer que existe un cierto punto en el espíritu desde donde la vida y la muerte, lo real y lo imaginario, el pasado y el futuro, lo comunicable y lo incomunicable, lo alto y lo bajo cesan de ser percibidos contradictoriamente. En vano se le buscaría a la actividad surrealista otro móvil que la esperanza de determinación de este punto" (Cit. en Cirlot, s/p).

En la mitología blakeana, el rechazo a las imposiciones de la razón se presenta, asimismo, como un requisito fundamental para superar la ilusión de esa 'sombra exterior que cubre la real superficie' (Jerusalén 83:47), y que nos aparta de la Eternidad. La liberación de los impulsos y energías proscritos por la razón se produce en esta zona intermedia que proporciona, además, los únicos recursos válidos para la creación poética y artística que promueve dicha emancipación, es decir, la intuición y la imaginación. El motivo bien lo sintetiza Adonis, al referirse a la obra mística de Ibn Arabí: "La imaginación que cada cual lleva dentro de sí es la única capaz de levantar la prohibición impuesta sobre un dominio en el que sin la imaginación no podríamos entrar. Sólo ella puede romper las 'rejas de la lógica"” (105).

37 Por ello, todos los impulsos -el amor y el odio, ternura y crueldad-conviven allí libremente, sin afectarse mutuamente gracias al poder del amor, que pertenece esencialmente a este plano de existencia. Ver: Foster Damon William Blake: His Philosophy and Symbols 423. En Jerusalén, 48:14, Blake señala: "Debajo del fondo de las Tumbas, que es el nudo central de la Tierra, hay un lugar en donde la Cosas Antagónicas son ciertas por igual (...) Beulah, en donde no puede surgir disputa alguna, Universo creado para los que Duermen" (117). 
Para terminar, y a modo de síntesis, consideraremos dos imágenes en las que William Blake elaboró visualmente estos principios:

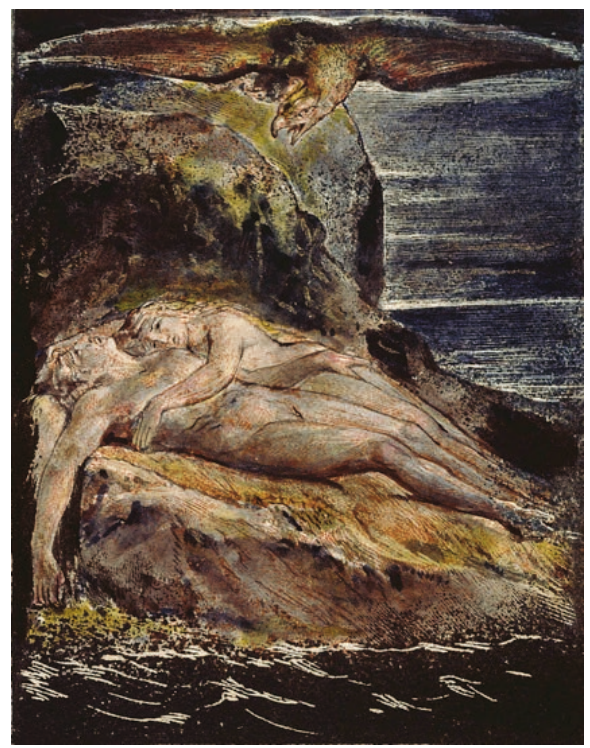

Milton, 38

La primeras de ellas (Milton, 38) muestra una pareja de amantes que descansa en una roca a la orilla del mar de Beulah, aparentemente después del acto sexual. La mujer duerme mientras el hombre, en un estado que parece ser el de duerme-vela, mira hacia arriba y observa cómo un águila desciende sobre ellos. En esta imagen se retrata el momento de la inspiración: por una parte, debemos considerar que Blake concibió la relación sexual como una actividad especialmente estimulante para la visión, en la que, además, se concilian algunos de los contrarios fundamentales, como lo físico y lo espiritual y el hombre y la mujer ${ }^{38}$. El águila, por otra parte, símbolo de la

38 Beulah, recordemos, etimológicamente, 'casada', 'desposada' es la región iluminada por la luna del amor, que se presenta como el lugar de los placeres sexuales y que, además, es símbolo del sueño y el inconsciente. En la obra profética de William Blake el sexo se relaciona con la armonía del universo, con la conciliación de lo físico y lo espiritual. Así como el ejercicio del poder poético, musical y artístico, la actividad sexual se presenta como 
altura, del principio espiritual (Juan Eduardo Cirlot 71) representa al Genio en la mitología blakeana ${ }^{39}$. La actitud del hombre respecto a ella nos remite a la consigna del Matrimonio del Cielo y el Infierno que esta imagen parece ilustrar: "En un águila miras una porción de genio. ¡Alza la cabeza!” (9: 15). Así, esta pareja de Milton resulta comparable con aquella del "Carro de la inspiración", de Jerusalén (46).

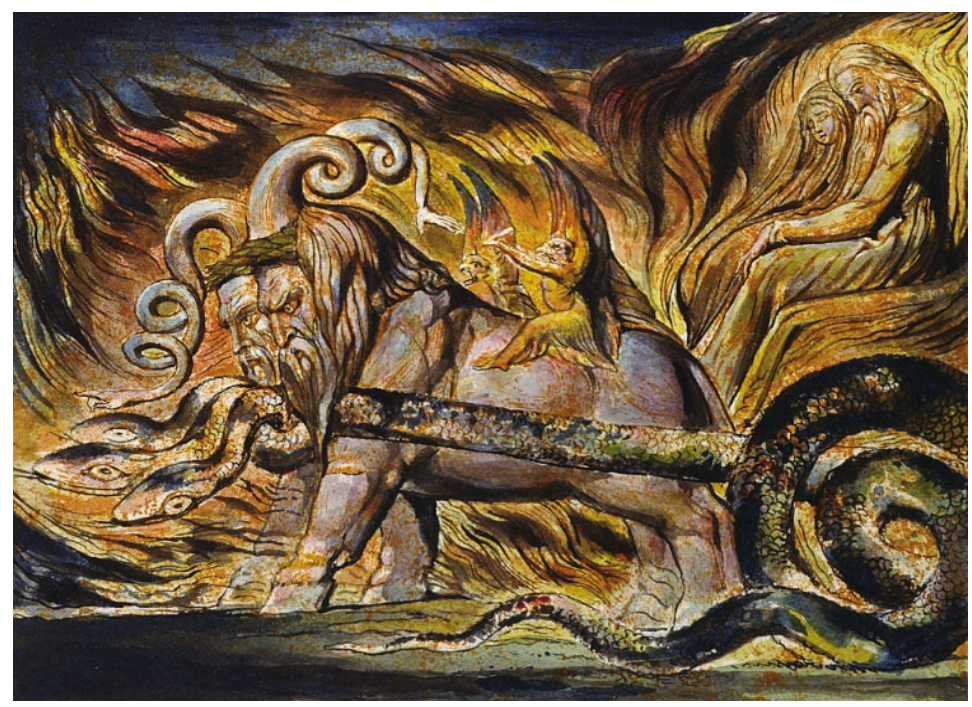

Jerusalén, 46

Dos toros con cabezas humanas conducen un carro de fuego, cuyas ruedas están formadas por serpientes, y transportan a una pareja que se asemeja mucho a la anterior: la mujer está totalmente dormida, mientras el hombre -en este caso más anciano- mira hacia delante, en un estado aletargado. Los toros llevan coronas de laureles en sus cabezas y cuernos que se curvan y

una forma de trascendencia hacia la eternidad. Además, el acto sexual induce, según Blake, a un estado mental propicio para imaginar y escribir poesía, ya que el cuerpo se encuentra relajado y la mente estimulada. Foster Damon, William Blake: His Philosophy and Symbols 102.

39 Ésta se ubica en el Norte (reino del espíritu). La paloma se ubica en el Este (reino de las emociones), mientras que la mosca pertenece al Sur (reino de Urizen, la razón) y la lombriz corresponde al Oeste (el reino de los sentidos). Foster Damon, A Blake Dictionary 112. 
retuercen como serpientes, y acaban por convertirse en manos humanas. Dos elfos alados y con cabezas de pájaro montan los toros, y uno de ellos ofrece una pluma a la mano que surge del cuerno correspondiente.

En este asombroso diseño, tanto las plumas como las coronas de laureles aluden a la poesía, mientras que la pareja se transporta casi inconscientemente en el carro de fuego, evoca la inspiración ${ }^{40}$. Esta imagen, por tanto, puede comprenderse como una representación visual del tránsito que permite la poesía, o más bien, aquella poesía que surge en el territorio de Beulah, que se identifica con el estado creativo. En aquel gesto concreto mediante el cual el elfo le entrega la pluma de escribir a la mano que surge del carro de la inspiración está contenida la superioridad primordial que Blake le otorgó a la intuición y la imaginación en el proceso de creación, una superioridad que se mantendrá como axioma durante el contexto más cercano del Romanticismo, pero que aproximadamente un siglo después, los poetas y artistas surrealistas también se esforzaron en demostrar. Estos proclamaron, como Blake, que el arte y la literatura debían contribuir a la conquista de una realidad superior, a través de la superación de las leyes de la lógica. Para ello recurrieron también a una 'región fronteriza entre el mundo interior y el mundo exterior', tomando las palabras de Max Ernst, donde las divergencias que la razón impone arbitrariamente entre 'los contrarios' se encuentran superadas, como en Beulah, y transcribieron con total libertad, suprimiendo completamente la voluntad consciente, 'cuanto vieron en dicha zona' (Ernst 177).

El fragmento del escritor y ensayista surrealista Michel Carrouges que hemos citado al comienzo manifiesta una profunda nostalgia por un paraíso perdido que es posible recuperar si hacemos 'desaparecer las fronteras' (Ernst 176) que nos mantienen confinados en este 'mundo hecho de escombros'. Tanto en la obra profética de William Blake, como en la mística sufí y la práctica surrealista, encontramos un 'intermundo' (Beulah, mundus imaginalis, surrealidad) en el cual los límites entre lo terrenal y lo espiritual se diluyen, rumbo obligado hacia donde debe peregrinar la conciencia para recuperar su condición verdadera, porque, como sostuvo André Breton: "La existencia está en otro sitio" (61). 


\section{BIBLIOGRAFÍA}

Adonis. Sufismo y surrealismo. Madrid: Ediciones del Oriente y Mediterráneo, 2008.

Béguin, Albert. El alma romántica y el sueño. México: Fondo de Cultura Económica, 1954 (1939).

Binyon, Laurence. The engraved designs of William Blake. New York : Da Capo Press, 1967 (1926).

Blake, William. Jerusalén. La Emanación del Gigante Albión (trad. Xavier Campos Vilanova). Barcelona: Universitat Jaume I, 1997.

Milton. Un poema (trad. Bel Atreides). Barcelona: DVD Poesía, 2002.

Breton, André y Paul Eluard. Diccionario abreviado del surrealismo. Madrid: Siruela, 2003.

Breton, André. Manifiestos del Surrealismo. Barcelona: Guadarrama, 1980.

Los vasos comunicantes. Madrid: Siruela, 2005.

Cirlot, Juan Eduardo. Diccionario de simbolos. Madrid: Siruela, 1997.

Cirlot, Victoria. "Juan Eduardo Cirlot, entre el surrealismo y la simbología". Agulha. 21/22 (2002): s/p. http://www.revista.agulha.nom.br/ag21 cirlot.htm

La visión abierta. Del mito del Grial al surrealismo. Madrid: Siruela, 2010.

Corbin, Henry. La imaginación creadora en el sufismo de Ibn 'Arabî. Barcelona: Destino, 1993.

Erdman, David (Ed.). The complete Poetry and Prose of William Blake. Nueva York: Anchor Books, 1988.

Erdman, David V. The illuminated Blake. Nueva York: Dover Publications, 1992.

Ernst, Max. Escrituras. Barcelona: Ediciones Polígrafa, 1982.

Damon, S. Foster. A Blake Dictionary. The ideas and symbols of William Blake. Providence, R.I.: University Press of New England, 1988.

Damon, S. Foster. William Blake: His Philosophy and Symbols. Gloucester, Mass.: Peter Smith, 1958 (1924).

Delumeau, Jean. Historia del Paraíso. Madrid: Taurus, 2005.

Haas, Alois M. "Sueño y visión en la mística alemana”. Visión en Azul. Estudios de mística europea. Madrid: Siruela, 1999. 13-31.

Heraeus, Stefanie y Deborah Cohen. "Artists and the Dream in Nineteenth- Century Paris: Towards a Prehistory of Surrealism”. History Workship Journal 48 (1999): 151-168.

Mitchell, W.J.T. Teoría de la imagen. Madrid: Akal, 2009.

Phillips, Michael. William Blake. The Creation of the Songs. From Manuscript to Illuminated Printing. Londres: The British Library, 2000.

Pierrot, Jean. Le Rêve. De Milton aux surréalistes. París: Borda, 1972.

Sung, Mei-Ying. "Blake and Surrealism". Blake 2.0. William Blake in Twentieth-Century Art, Music and Culture. Ed. Steve Clark, Tristanne Connolly y Jason Whittaker. Londres: Palgrave Macmillan, 2012. 102-119. 